\title{
CONSCIOUSNESS IN EXTREMITY: DISCOURSE ON MADNESS AMONG THE TABWA OF ZAIRE
}

\author{
Christopher DAVIS-ROBERTS *
}

University of Michigan, USA

The madman makes it possible for us to grasp the radical potential of consciousness at its limits. $\mathrm{He}$ contradicts the other person's discursive thinking towards the virtually inarticulable or unthought self.

The Lakeside Tabwa of Shaba, Zaire, apprehend madness in three rather different, discursive domains. There is, firstly, wazimu, or its 'mature', incurable form, kizenzezia, considered as a fact of social life. It is seen as inverting the norms or functions of personhood and undoing those of mentality. It breaks down reciprocity, it is the negative function of 'Death'. Secondly, it is in the prodromal illness, mubulibuli, and certain related emotion states, that madness appears as the artefact of another's malicious and intrusive 'Desire': the madman is said to have 'closed anger' in his heart alienating him from ongoing experience and interaction. Finally, in the diviner, the 'otherness' of gaze and speech is transformed into the normative power of clairvoyance bringing about its own logic and historicity. Here, the inversion of personhood becomes an emblem of insight and 'Law', but at the risk of insanity. The ethnographic encounter with the very otherness of the thinking of madness and of another culture toward the unthought itself is, in a sense, epistemogenic.

\section{Introduction}

'The stark impossibility of thinking that'

Michael Foucault's Order of Things arose from the peal of laughter with which he chose to encounter in wonderment and in one great leap the limitations of his thought, as our thought, "the thought that bears the stamp of our age and our geography'; a limitation made perceptible 'as the exotic charm of another system of thought' and felt as 'the stark impossibility of thinking that' (1970: xv). The work ends with a consideration of psychoanalysis and ethnology as two 'counter sciences'

\footnotetext{
- Author's address: C. Davis-Roberts, Dept. of Anthropology, Center for Afro-American and African Studies, 1054 L.S.A., University of Michigan, Ann Arbor, MI 48109, USA.
} 
which flow in a direction opposite to that of the 'human sciences' [1], which 'lead (these) back to their epistemological basis', and which "ceaselessly "unmake" that very man who is creating and recreating his positivity' by means of them (ibid.: 379).

The quality of the two as 'counter-sciences' derives from their positive delineation of that finitude upon which all the other human sciences are based; their outlining of that 'unthought' toward which the modern cogito constantly toils, but cannot attain. Psychoanalysis constitutes for the human sciences the unconscious as 'their most fundamental object' (ibid.: 372). In the mechanisms, forms or processes that give subjectivity its shape, psychoanalytic theory not only demonstrates that there is 'always something still to be thought in what had already been thought on the manifest level' (ibid.), but functions as well to reveal 'the simple fact that it is possible for there to be system (and therefore signification), rule (therefore conflict), norm (therefore function)' in that which lies beyond thought (ibid.: 374). Just as psychoanalysis is situated with reference to the unconscious, so can ethnology be located with reference to historicity; the 'fundamental object' constituted by the former counter-science is thus complemented by the 'external boundary' to thought that is articulated by the latter as the law of time (ibid.: 372 ). 'Ethnology has its roots ... in a possibility that properly belongs to the history of our culture, even more to its fundamental relation with the whole of history, [one which] enables it to link itself to other cultures in a mode of pure theory' (ibid.: 377).

In the ethnographic encounter with madness, the limitation of one's thought is made perceptible twice over: first in the figure of the madman himself, then in the constitution of madness as a discursive object within the context of the culture under study. It is as if modern thought's 'fundamental object' has been paradoxically relocated to its 'external boundary' with the consequence that analysis becomes a

[1] Foucault defines the human sciences in terms of their analytic function and location. Thus: 'The human sciences are not, then, an analysis of what man is by nature; but rather an analysis that extends from what man is in his positivity (living, speaking, labouring being) to what enables this same being to know (or seek to know) what life is, in what the essence of labour and its laws consist, and in what way he is able to speak. The human sciences thus occupy the distance that separates (though not without connecting them) biology, economics and philology from that which gives them possibility in the very being of man' (Foucault 1970: 353). Within this general yet precise determination, they may be roughly described as psychology, sociology, and the study of literature and myth. 
movement toward an unthought which is, in fact, another culture's thinking toward the unthought in itself. Within the very alterity that is 'the exotic charm of another system of thought', madness is constituted as an object which is itself 'other' to functions and norms, conflict and rules, signification and system. The penetration of this domain, i.e., the effort to articulate what is virtually inarticulable in it, carries the terms of our thought to their 'limit, to that of their imaginable expressions, after which everything will be changed' (Valéry 1972: 15). At such a point, we find that even the three figures which are 'in fact the very forms of finitude as it is analysed in modern thought' - viz. Death, Desire and Law (Foucault 1970: 374) - can themselves be reconstrued. Foucault suggests that these lie in the region where the representation by which men know (or seek to know) themselves and their lives 'remains in suspense, on the edge of itself, open, in a sense, to the closed boundary of finitude' (ibid.). It is here that 'we find outlined the three figures by means of which life, with its functions and norms, attains its foundation in the mute repetition of Death, conflicts and rules their foundation in the naked opening of Desire, signification and system their foundation in a language which is at the same time Law' (ibid.).

The 'double negative' that is the ethnographic encounter with madness permits us to reconstitute Death, Desire, and Law less as 'figures of finitude' than as 'virtual images' (Freud 1953: 611) of consciousness in extremity. Having effects in the domain of social relations, construed as objectified moments of social experience, taken as models for social knowledge, the three take on a different aspect. Death becomes the death of reciprocity, Desire becomes the desire of a being genuinely other than the patient, and Law becomes the pronominal, logocizing emblem of truth as made manifest in divination. As a consequence the absolutes we think we glimpse beyond time and thought come to stand revealed as nonetheless bearing the trace of our own history and tradition, traces which the movement of modern thought has yet to efface. These are the marks left by the intervention of the notion of the text in the very idea of a subject: an intervention which makes possible the definition of madness as an illness of subjectivity (i.e., as a distorted or foreclosed historicity in the subject); an intervention whose limits can be seen only dimly by the light of a reality so enchanted or poeticized that language is not divided from the world, not even by being 'written' on it. 
The Lakeside Tabwa of Shaba, Zaire [2], are a matrilineal, virilocal group who live primarily by subsistence farming (principally of manioc) and fishing the rich waters of Lake Tanganyika. Among the sane live the mad, sufferers from wazimu or its 'mature' (kukomaa), incurable form, kizenzezia. Some, who are constantly deranged, wander in and out of the periphery of social life, living in no fixed abode and eating by virtue of the charity of kin. Others live within society, but wander in and out of madness, becoming deranged twice a month at the new and full moons [3]. In their affliction, such people are not only figures in social history (i.e., those about whom there is story to be told), they are also incarnations of enigma. Simultaneously subjects and objects, they make directly apprehensible both the terrible limitations and the radical potential of consciousness in extremity.

As a type of thinking toward the unthought, their articulation of consciousness in extremity is discussed by BaTabwa in three rather different discursive domains. First, there is consideration of wazimu itself as a fact of social life, and the problems it poses to the functions and norms of personhood. Then, in the consideration of a prodromal illness mubulibuli and certain related emotion states, madness is articulated in the dimension of intersubjectivity, as a figure for social thought marking the movement where conflict meets rule. Finally, in the consideration of the diviner's accession to clairvoyance, an accession made perilous by the risk of becoming mad, insanity is articulated as an emblem of social knowledge, that is, of signification and system.

\section{Wazimu as fact of social life}

In its constitution as a fact of social life, wazimu is first of all an illness entity whose multiple symptoms are fixed by Tabwa medical discourse. However, bizarre behavior which does not conform to the description is not considered a manifestation of illness, but is regarded as simply the

[2] The data on which this paper is based were gathered during four years of field research in the area, covering the period 1974-1977. Funds for the study were derived from a U.S. Public Health Service Training Grant, a Wenner-Gren Grant-In-Aid, and a Social Science Research Council Foreign Area Fellowship. Opinions expressed in the paper are those of the author.

[3] BaTabwa say these are the two times of the month when all chronic illnesses are exacerbated. 
'condition' ( hali) of the person [4]. The following exegesis of wazimu is a composite derived from numerous discussions with diviners and lay people.

The start of wazimu is the heart that pounds (rho kupapa). If you take hold of the sick person, you can feel it beating. The heart 'splits' (kupasuka - this is the pounding) and comes out the middle of the top of the head (katikati ya kichwa) [5]. If it comes to the eyes, it changes, it is other. It is as if fire comes to the eyes, as if the person sees fire, and the person begins to see 'other things' (vitu vingine) or things of 'another kind' (vya namna ingine). He sees things others do not see. He speaks with 'others' (ba-ingine, literally 'people of otherness'). You are there but conversation is with 'others', and the person no longer understands or responds to what people are saying to him.

Wazimu is characterized by violence. The person has become fierce or fierceness (makali) himself, and he sees fierce things. He takes up a machete because he sees people coming at him with machetes and so he readies himself. But it is really his kinspeople. He may see ten people in the space ahead of him, but you see no one. The least disturbance will cause him to grab a stick or knife and begin to kill children or goats. Friends will grab you, but you will see them differently. They will be enemies. The person has a desire to run off to the bush, and has to be tied down. He wishes to remove his clothing, walks about naked, eats filth, grasses and leaves. He will perhaps even eat feces. One must be careful to tie the person with cords, to prevent his running off. If one is mistaken and the person gets away, only someone who knows medicines may get him back. He does this by going to the bush and gathering certain leaves. These he smokes, and he blows the smoke in the direction of the wazimu. Slowly the person comes close, and finally they are able to bring him back to the village. One may also call him by blowing on a medicated animal horn, as with Tulunga [6]. Once he has

[4] Thus, the behavior of a young man who (upon losing a suit against his father) came home, stripped his mother naked, beat her and broke all her pots, was shrugged off by other people as 'his condition' (hali yake). However, there was commentary to the effect that he would probably find it difficult to marry, since a stranger could only expect worse treatment; and there was speculation about whether or not he might be cursed with bad luck because he had seen his mother naked.

[5] This is also the place where the soul leaves the body at death, as well as a place where sorcerers' medicines may enter.

[6] This is a type of divination whose relationship to madness is discussed at greater length below. 
come to town, one begins to treat him with (ritual) medicines. Some are smoked, others he is given to lick and still others he wears.

Each person who has this illness has a 'friend' (rafiki) [7] to whom he is especially attached. This person is the 'origin' (asili) of the illness, and it is this person against whom the greater part of the wazimu's violence is directed. To begin treatment, the person who is his 'friend' gradually comes closer and closer to him (for he may kill people) until he is finally able to offer the sick person food or medicine, then other treatments may ensue. With luck this will last only a week or so and the person will recover. One must be prompt to divine and find the path of the medicine (i.e., the appropriate therapeutic course). If the wazimu fails to get better, treatment will at least get a person to settle down (kuinama - to lower the head, hence to be submissive) and no longer be violent or desire to walk naked.

If the person is lucky, he will recover, but sometimes this does not happen. The medicines will fix him so that he does not run off, and so that 'he recognizes himself as a person' (anajitambua kuwa mutu), and no longer feels the desire to remove his clothes, or eat filth, etc. But he is not well, the wazimu has 'matured'. To treat a person like this is worthless, and nobody bothers with medicines any more. The illness has matured, and has become 'like the condition' (kama hali yake) or 'like the character' (kama tabia yake) of the person. He will never be any other way. Some days of the month he will be 'quite a person' and to speak with him, you will speak normally. But starting about three days before the new moon - or at the new moon and then for three days, it varies from person to person - the person will just sema-sema (i.e., speak constantly and nonsensically). They will shout obscenities, or speak to no one, and will stay up all night talking to and insulting no one. Once the moon has risen a bit in the sky (i.e., a few days after the new moon), they stop. They remain quiet for two weeks, and start again for another three-day period, when the moon 'goes into the lake' (i.e., when the moon rises out of the lake, in the east, at the full moon).

This condition is called kizenzezia, which is the name given to wazimu when it has matured. In it, wazimu is 'the health' of the person

[7] The use of the term rafiki is significant because it is exclusive to this context. The usual term of reference for any one of a pair of human beings is 'counterpart', a word which stresses the equivalence and reciprocity in social relations, despite the fact that the members of the pair may stand in complementary roles to one another (i.e., mother-child, husband-wife, etc.). 
( uzima wake), and the person never recovers. Treating him with medicines is useless, as he cannot be cured. He just stays that way, getting worse at the new and full moons, until he dies. Even if the person is cured a kilema (defect, deformity) must remain. Perhaps the person will be makali (fierce, sharp-tempered) or quarrelsome. It is not possible for a person to recover from this without a kilema. With some people, the kilema of wazimu will be apparent only if they drink or smoke marijuana. This is why these things are forbidden to a person who has had wazimu; no matter how long ago he has had it.

Critical to our understanding of this description is a comprehension of the perspective from which it is drawn. It is a perspective essentially external to what we understand as subjectivity, one which articulates the inner experience of the patient only in schematized, minimal ways.

All sufferers from wazimu are assumed to be seeing the same thing. Their experience is thus constituted as a reduction rather than a heightening of personal idiosyncracy, and yet profoundly 'other' to ordinary understanding. The common use of the phrase 'of another kind' (ya namna ingine) when speaking of the mentality of the mad conveys the sense of a basic alterity which somehow must be accepted as such. Tabwa discourse relating to madness is thus more a talking 'about' it than an attempt to speak with it.

Behaviorally, wazimu can be described as an inversion of the outward aspects of personhood (umutu). The sick person wishes to run from village to bush, to remove his clothing, to shout obscenities, to be violent, and to eat filth. When mad, as people put it, he "is a person in terms of body only; in terms of mentality (he) is an animal' [8]. Madness is thus constituted as having place less in the interiority of the patient's being than in the domain of his being-in-the-world.

This idea is duplicated in the somatic aspects of the illness, for the point at which it begins is not solely when the heart 'splits', but when it also comes out of the top of the head, a point through which inner being has contact with the world. This is, in addition, the point by virtue of which we can begin to grasp an idea of the subject that is, for us, difficult to think, i.e., one where being is literally objective, where

[8] 'Kwa mwili ni mutu; lakini ni mutu kwa mwili tu; kwa akili ni nyama.' It is important, however, to bear in mind that the idea of madness as an inversion of personhood is quite different in its implications from the concept of madness as a regression to an earlier (hence, more 'natural' or less socialized) developmental stage. 
mentality is construable as an object among other objects in the world (since consciousness may be affected by ritual substances which enter through the top of a person's head but without his perceiving it).

Finally, the most enigmatic aspects of wazimu derive from its localization in the gaze and in speech. It is constituted as an illness of faculties, rather than of the materiality of the body. People make note of this when they compare madness to other illnesses 'of the head'. With wazimu, the dilemma is that 'one cannot say that the patient should be incised (hence, medicated) at a certain place, a vein'. Its ephemeral, transient qualities lie at the center of its mystery. One diviner/practitioner put it thus: "If the person speaks to "others", if he laughs at nothing, sings, whistles, this is the illness itself. It is an illness, it is not part of the body. If that tree gives birth to the other, then the other dies, how can you know what - if anything - it was?'

Through the image that it is 'like fire' [9] which comes to the eyes, BaTabwa articulate the idea that madness is a processual presence which, like the intoxicating effects of drink or drugs, must be effaced if the patient is to be cured [10]. The medicines employed in the attempt to make the patient 'lower his head' or be submissive (kuinama) include those which have' the specific meaning of 'extinguishing' (kuzimisha) or cooling marked states [11].

In addition, the two faculties in which the processual presence is localized are those particularly associated with knowledge and with transformation. BaTabwa speak of esorteric knowledge as 'to have eyes' (kuwa na macho). To know is to be possessed of a gaze by which one can recognize things for what they are, whether this be the identities of medicinal plants, the diagnosis of illness occurrences, the illusions created by sorcerers, or the sorcerers themselves. Knowledge is thus

[9] In other domains of medical discourse fire, speech, and sexual generativity are all transformative analogues; entities which are in fact processes whose unique characteristic is their explicit connection of being to becoming.

[10] The effects of marijuana are particularly associated with madness. In fact, the two are identical except for the causative substance - hence, presumed transience - of the state caused by bangi. One person may deeply insult another by implying that his perception of/behavior in a given conflict is due to marijuana smoking. By thus implying that he is like one mad, he (i.e., his intention or efficacy as an agent) can be utterly dismissed and consequently the person himself deeply wounded or infuriated.

Drunkness is the lesser analogue. Relating to madness only in the unrealistic extravagance of feeling/perception it produces, it is a folly people find quite amusing in the abstract.

[11] Interestingly the same medicines are also used to extinguish another extremity of consciousness - this one transgressive - viz, a chronic tendency to thievery. 
equated with the perception by which the world is constituted to the subject.

Speech is the affecting counterpart to the gaze. As articulations of intention, utterances can have direct effect upon processes unfolding in the body, either promoting or subverting them. Similarly, invocations spoken to or through special objects (i.e., shrines, amulets) can have an effect upon those agents (e.g., ancestor spirits, avenging ghosts, other persons) whose intentions determine the unfolding of events. Speech is thus a medium through which the world is constituted by the subject. With the commonly held idea that at his death a person's voice goes into or becomes light, the two faculties are brought together. In their union we may glimpse a world in which the determinate being of things derives as much from the field of predications surrounding them (a field in which knowledge and intention are combined) as it does from the things themselves, a feature which has a critical bearing on wazimu's status as an emblem of social knowledge.

Thus, madness is not only defined as an illness of personhood more than of subjectivity. It is also an illness of mentality (akili) - of intelligence or intellect - rather than of affect or instinct. This point is further developed in the exegesis of the term for wazimu's mature form, kizenzezia, a term deriving from an illness or condition of chickens. In one conversation, kizenzezia was described thus: A chicken which is this way has no mentality to lay all her eggs in one place and then to set upon them, hatching them out. This sort of chicken will lay one egg in one place, and another in another. She will lay them anyhow (ovyo), and in places where the eggs are not safe. Then, too she will not set, but will just stop laying and then go about her business without a thought to them [12].

If madness is an illness of mentality, then, this description makes clear that it is one whose specific effects are regarded as deconstructive more than as degenerative. Depicted is not so much a deterioration within a mind as the specific absence of that mind's constructivist aspects, aspects which not only involve the putting of things together, but also the doing so toward some future result. Implied is the absence

[12] The first sentence is literally to state that the chicken 'has no mentality of saying that she put all her eggs together that she give birth' (hana akili kwa kusema aweke mayai yake yote pamoja azae). Tightly interwoven in it is the notion of putting things together toward some future end i.e., building through or over time - and the connection between this aspect of mentality and speech. 
of a properly generative self-consciousness, and when transposed to the domain of human life, such a mentality becomes one which deconstructs social relations. The circumstances of Ngandwe Kaluba, as discussed by others in this passage from field notes, mark a case in point.

When she first was stricken with wazimu, she had been a real terror. She would insult people and shout obscenities. They had had to bind her with cords. She had tried to nun to the bush. She had thrown rocks at people and had beaten children.

They had called a mfumu (diviner/practitioner) to treat her, but this had only succeeded in calming the thing somewhat. Now, she is just crazy twice a month, but she insults her mother vilely.

Muzame said he'd passed the two of them working in their fields a few weeks ago, and had had to pause and be astonished ( $k$ ushangaa) at the obscenities Ngandwe hurled at her mother she weeded. He had been astounded, and had never seen or heard the like. She did not 'know' her mother (hamujui mama yake) and just insulted her as if she were nothing. He said that when that woman's mother died, she would have a very hard time, as no one in her family would wish to receive her because of her mouth (i.e., insults).

Then, to, Luvunzo added, she hated for her mother to speak to anyone on the path when they were coming from the field or going to it. She liked for her mother to predice (tangulia) her, and if her mother dared to stop and talk to anyone, even in passing on the road, she would strike her or give a push, and say, 'Let's go! Let's go!' in a rude voice, forcing her mother to go on.

Throughout all of this, her mother just remains quiet and says nothing. It is just the illness, what can one do? But everyone feels pity for her mother, because she is mightily afflicted by this illness of her child.

Katato said that she had been quite as abusive of her father as she had been of her mother, until 'God ransomed him in death'. She would see him returning from the fields and say such things as 'Oh, so you're back. Let's go sleep together now.'

This case adds to our understanding another layer, for wazimu is not only an illness entity articulated in Tabwa medical discourse. It is also a social reality with which people must live. Ngandwe does not 'know' her mother. By insulting her, she treats her mother as though she were 'nothing'. Her incestuous remarks to her father had a similar effect: he, too, was as if 'nothing' to her. While this exquisitely inverted behavior appears to our post-Freudian thought as a type of hyper-recognition of certain individuals, the emphasis in Tabwa discussions of the matter is on the way in which such behavior deconstructs the precise differentiation among persons by virtue of which kinship forms the basis for reciprocity.

In other discursive contexts the statement that one person is "nothing' to another indicates in a superficial way that the two have no connection of kinship (real or classificatory) on the basis of which to 
structure and limit enduring relations of reciprocity. There is no precise social distance that both separates and unites them, and there is no history of or necessity for interaction. In this context, as in the context of conflict, the term also implies the social violence of repudiation, a lack of restraint that collapses the distinctions of which the web of kinship is made. To be 'nothing' is to have been actively deconstituted, dis-recognized in one's own personhood. It is a marked state.

Hence, when treating her parents as 'nothing', Ngandwe, like all the mad, demonstrates a deconstructive extremity of consciousness which is such that she herself becomes a 'bleep' or cipher in the system of reciprocity. The inability of the mad to recognize themselves as persons finds its equivalent in their inability to constitute the personhood of others. The pity that people feel is for those who must act as kin to one utterly unable to 'know' them. It is for those who must fulfill the functions and meet the norms of reciprocity for no other reason than to do so.

In the domain of social life, then, madness is established by BaTabwa as a consciousness which inverts the norms or functions of personhood (not subjectivity), and which undoes those of mentality (not instinct). When thus constituted in the field of social relations, the finitude that is the organism's 'mute repetition' of Death can be transfigured, changed into the repeated deconstruction of reciprocity by a consciousness in extremity. In the form of the burden that madness imposes upon the sane, this Death becomes the means by which a virtual image of reciprocity as such is cast up in ongoing social relations.

\section{A figure for social thought}

If wazimu itself is constituted in the dimensions of personhood, mentality and reciprocity, it is in the prodromal illness, mubulibuli, and related states that we find extremity of consciousness articulated in terms of affect and experience. Discourse in this domain stresses the moment when conflict envelopes rule and the subject's being-in-the-world is transformed by the Desire of another. The description of mubulibuli is as follows.

The person feels his heart pounding. Perhaps it will come out through the head. If sleeping or trying to, the person will no longer be able to tolerate loud noises near him. If people are drumming, he will 
drive them off. Or he does not like having noise near his head, such as being called or addressed in a loud voice. He also cannot be awakened with force, grabbed and loudly called. In response to all these things he may whirl about and beat one. In response to abrupt awakening, the person may faint and only slowly will he recover. He may also have 'many thoughts' (mawazo mengi). This state can go on for a long time; even as much as a year or more. But if it is not treated the person may gradually become more and more fierce; it will change into wazimu.

This description may be divided into two significant elements, each of which can be amplified by pursuing its connection to other states. First is the sensation of the pounding heart (rho kupapa), a feeling also characteristic of wazimu. BaTabwa say that one may feel this if one is startled or is frightened. In these situations, the sensation is not indicative of illness. However, this feeling also happens when one is spoken ill of by others, or when others triumph in one's misfortune; two types of social violence that are covered by a single word, kusimangwa. Under these circumstances, one may feel pain in the heart as well as pounding. The lack of tranquility (amani) felt at such times is called mutima wapota, 'twisting of the heart', and is recognized as a state that can be prodromal to mubulibuli. This is especially the case when the twisting of the heart derives from anger (akisirani, asira) the emotion which, as fierceness (makali) or irritability, constitutes the second significant element of mubulibuli.

When they speak of the emotion, BaTabwa relate anger to the experience of having been wronged, unjustly treated, as when a person strikes one's child without reason or when someone commits adultery with one's spouse. A person deeply resentful is said to have 'closed anger' ( kufunga asira) in his heart. When in this state of mind, a person 'sits in one place, does not speak, does not eat, does not go very far. One says "he has closed anger". He sits with bad thoughts in his heart. If they tease or vex him (kuchokoza), he may rise up to kill'.

As with mubulibuli itself, then, the closing of anger in the heart is discussed in association with irritability and many thoughts. Both states of mind are characterized by an indefiniteness of object which places the subject's consciousness in a position of extremity. In it, he is alienated from interactions and so is 'closed' off from the processual time inherent in ongoing experience. In its relation to specific cases of madness, this situation of consciousness in extremity presents an inverse aspect. At this level, we find that the cause actually attributed to 
almost all instances of wazimu is sorcery deriving from one whom the sick person has previously wronged, always by adultery. Madness is thus the artifact of another's desire for revenge. Yet, this desire for revenge is itself a type of extremity in consciousness; a grudge ( fitina) related to anger but deeper, and deeply attached to its object. BaTabwa are quite clear about it: 'If a person commits adultery (kufanya upuzi, literally "to do folly") with your spouse, you don't wish to see the person any more. If you hear the person is sick you will be happy because they might die. Even if you don't see the person you may think of them and become angry again, just at the thought.'

Complementarily, one must know that the commission or adultery can only result in a similar feeling in others. In one conversation it was put thus: 'With fitina one would have to know that the other person felt this. Fitina would occur if, say, one had committed adultery with another man's wife. If that man found out about it, even if one had been friends before; the friendship would be ruptured. Though one would have admitted one's guilt and paid reparations, and though he would have accepted the money and relations been apparently restored, you would know that in his heart, fitina was what he felt. Even if he did not say anything, and continued to speak to one, one would either see it in his behavior or just know that it would have to be there, on the basis of knowing what one had done to him. He could not feel any other way, and in the end he might be one to get medicines to kill or derange you. You therefore try to avoid him.'

Crucial to these descriptions is the ineffaceability of affect. Despite admissions of guilt and restitutive actions, the ill feeling remains. As it was put in another discussion, the wronged spouse has been 'transformed into a fool' (unanigauza mupumbafu) by one's transgression, and the intensity of animosity derives from their experience of this diminution. Hence, though not itself explicitly discussed in terms of affect and experience, wazimu can be seen as the figure underlying a temporal extremity of consciousness in the domain of conflict and rule. Both in the states which may be prodromal to wazimu and in the emotions one's own transgression can cause in others, there is a fixity which draws consciousness out of experiential time. In the former it is the indefiniteness of object; in the latter, the ineffaceability of affect. Both stand opposed to the ordinarily transient irritation which is part and parcel of social life. Referring to it by the term chuki, people say this sense of irritation can occur when, for example, 'you see another 
coming just at the time of eating or drinking, because you see that there will not be enough for yourself. You will have to eat or drink less. Perhaps you say to your wife that she should not bring out the food until after the person has gone. Or perhaps you call him anyway. In either case after the food is eaten, the chuki passes and one is friends again with the person.'

In sharp contrast to this stands the chuki of the sorcerer. Like all chuki, it is kept a secret, for the feeling itself is a diminution of others and its expression can only be taken as insulting. Unlike normal chuki, however, that of the sorcerer is so far from being transient as to be wholly formative of the individual's character. In addition, it may become attached to one without reason, or on the basis of insignificant conflict, and then endure until its object dies. As it was put in one witty consideration of the subject: if a sorcerer feels chuki toward you, only when you are dead will such a person be happy; only then does his anger with you finish. If he gets very tired of seeing you, he may make medicines to kill you. He will be the first to arrive at your funeral and will even help with the digging of the grave, but only so as to be the more quickly rid of seeing your face.

Taken together then, mubulibuli and related emotion states form a constellation centering around the figure of wazimu and articulating the intersubjective domain where conflict envelopes rule. Here, it is not the affect as such which is in question; for the anger, irritation or grudge appear entirely comprehensible, indeed, even expected, on the simple basis of transgressive circumstances commonly and repeatedly experienced by everyone. Instead, it is the fixity of feeling which marks the extremity of these states of consciousness.

As a figure for social thought, wazimu enables us to see how the finitude that is the 'naked opening' of the subject's sexual Desire can be reconstrued. Taken as a subject's vulnerability to the destructive desire of others, it becomes a virtual image of violation. In both the closure of mubulibuli and the derangement that can derive from sorcery, what has happened is that the person has become the object of someone else's (malicious) pleasure, a token in someone else's game. Articulated from the perspective of both the wronged person (kufunga asira) and the punished transgressor, this objectification of being casts up in experience and makes available for thought the 'as suchness' of the very moment when desire overflows limits and swamps restraint. 


\section{Emblem of social knowledge}

In considering the ways in which people may become diviners, we complete our understanding of the role played by wazimu in Tabwa discourse. This is the domain of social knowledge, i.e., the area in which knowledge is established about and through social relations. It is here that the features of madness are rearticulated as cultural constructs. By means of this appropriation, the hollow inversion of personhood becomes an emblem of insight, and the 'otherness' of gaze and speech is transformed into the historizing power of clairvoyance; but only at the risk of insanity itself.

Each of the two principle types of divination used by BaTabwa is significantly connected to wazimu. Bulumbu diviners possessing spirits may make their initial appearance as a derangement which can become permanent if it is not properly managed. Tulunga diviners are given medicines which make them behave as if mad during their ceremonial initiation. Here, the overturned consciousness, characteristic of wazimu, becomes an aperture through which signification and system can reestablish the continuity of lives disrupted by affliction and/or misfortune. When accepted by clients, the diviner's pronouncements become a Law which reorders and so develops the histories of lineage groups.

The connection between spirit possession and madness is made in the consideration of specific cases of derangement. At this level the madness caused by a spirit must be distinguished from other wazimu if cure is to be possible. Distinction sometimes can be made on the basis of particular features, such as the singing of Bulumbu songs during the illness. Most often, however, the link between the two is established after the fact of cure has confirmed the truth of divination; or the failure of cure by non-ceremonial means has left the person permanently deranged.

Treatment of this form of madness, like treatment of all illnesses deriving from possessing spirits, consists of a ceremony in which the spirit itself is 'put in order' (kutengeneza). To drumming and singing directed by adepts who are themselves possessed, the patient is 'mounted' by the spirit, which then speaks its name and states the reason why it has come. Once arranged, the spirit may possess the person when it is called, or when it chooses. In either case the consciousness of the person is said to have been 'overturned' (kupindua), so that he himself is unaware of what the spirit says or does when it 
possesses him. This image of overturning is precisely that most often employed by people to refer to that state of madness. Here, however, the overturning results in a capacity to see things others do not see, to know things without having learned of them mundanely.

With the initiation of Tulunga diviners, medicinal plants induce a state of mind which BaTabwa characterize both as resembling madness and as bringing the novice periolously close to becoming mad. The person trembles violently and is agitated. Everything glows before him as with an inner light. Stripped of most of his clothing he runs about wildly, searching for two medicine-filled horns which have been hidden by the adepts and which he must find if he is to accede to his power. He is said to hear nothing other than the sound of the bell attached to the horn he is seeking. In this state of mind, the novice can be controlled only by the use of a medicated whistle blown by a senior adept. Failing this, he would run off to the bush and be lost. Indeed, the novice's vulnerability is such that his return to sanity is guaranteed only by the strength of his mentor's medicines, for a sorcerer can render him permanently insane by simply stamping his foot on the ground at this time.

In the domain of social knowledge, then, madness is constituted as the emblem of insight. By 'putting -it in order' and by risking it, particular individuals make of their consciousnesses locations whose very extremity, whose 'otherness', permits a mediation between specific instances of problematic illness and the affecting agents (ancestors, spirits, avenging ghosts, sorcerers, etc.) which have caused them. Such agents are said to present themselves directly to the diviner in dreams or in his possessed state and to tell him why then caused the misfortune in question. There is thus a respect in which diviners can be said to look 'through' particular circumstances to see and to speak of the predicating history from which those circumstances derive.

The ceremonies required by divinatory pronouncement can similarly function to change the predications on the basis of which people live. Grudges and transgressions must be confessed; quarreling and ill will within the lineage group must cease, at least temporarily, if the ceremonies are to work and the patient be cured. Indeed, it is partly by considering what they will have to do to accomplish this that people determine whether or not to accept the diviner's insights.

The consciousness of the diviner thus becomes the means by which signification and system are rearticulated in the ongoing of individuals. 
It is an aperture by virtue of which people may glimpse the extremity of determinate cause and so come to reorder their more proximate relations. If, however, the diviner articulates Law, it is a law whose particular form is an emblematic, as 'mad' as madness itself; for what is presented in divinatory seances is not an analysis of circumstances, but a pronominal structure of truth. The diviner will describe only the barest situational outline; saying, for example, that he has seen 'two women, an older chasing a younger one', or 'a snake looking down onto a bed from the wall above'. It is to the assembled group of kin to work on the Law presented in this condensed, poeticized mode and in the working to find their liberation from affliction.

In its capacity as an emblem for social knowledge, then, madness becomes a model for the generation of lineage group history. The diviner's extremity of consciousness permits the reestablishment by signification and system of social relations whose order has been disrupted by the discontinuity of problematic illness. Here, Law becomes the virtual image of determinate agency actively expressing itself through affliction, and history can be seen as the constitution of an ongoing present.

\section{Conclusion}

In the analysis of Tabwa thought toward the basic 'otherness' of consciousness in extremity, we find a movement which resembles that of our modern cognito with endless pursuit of the unthought. Indeed, implicit in the very term 'resemblance' is the delicate play between identity and difference by which we are most enlightened; for the discourse under discussion here operates beyond textuality, even though it can be made into a text. As a consequence, it presents a type of human science whose 'economy' we must struggle to comprehend.

Rather than figures of finitude establishing the limits of representation - figures which can only be detected by an accumulation of examples (repetition), a sensitivity to lacunae (deconstruction), or an analysis of relations (grammar) - we find instead the virtual images cast up by extremity, images in which function and norm, conflict and rule, signification and system may be glimpsed as such on the very surface of social life. Like the truth of an enchanted reality, it is all there for those who 'have eyes' ( kuwa na macho) to see, or ears to hear the discourse of 
others. This is to say that in its capacity as a sort of archaerepresentation, extremity does not silence speech, but provokes discussion. If we wish to locate the non-textualized human sciences in cultures like that of the Tabwa, we may do so by focussing on conversations which are, in a sense, epistemogenic; i.e., ones in which people employ what they know of their culture to comprehend the aporias presented by their lived experience.

What discussions, such as those on madness, generate is not the proliferation of texts but the continuous constitution of (sane) persons to and by each other; the redelineation or reconsideration of aspects of culture; and the ongoing transformation of particular gazers and speakers by their experience. The movement generated by non-textualized human sciences is thus the displacement of the persons in whose consciousness these sciences are lodged. This includes ethnographers when they are present.

It is the ethnographer who writes things down and who is able, therefore, to reconstruct from widely separated conversations about apparently diverse topics the several discursive domains in which madness figures as an entity. In her text, she constitutes something present in the field experience, but which is both thought and unthought there. It is dispersed precisely. because conversation is both too regional and too playful in its movements for any one discussion to include the whole. What she presents as Tabwa thought toward consciousness in extremity, as non-textualized human sciences, is thus an artifact of her textualization. However, it is a textualization whose purpose has been to demonstrate the ways in which another form of thinking about thought can be derived from the content of speech, a form which can address with increased directness the limits of our own.

\section{References}

Foucault, Michel, 1970. The order of things: an archaeology of the human sciences. New York: Pantheon.

Freud, Sigmund, 1953. The interpretation of dreams. New York: Basic Books.

Valéry, Paul, 1972. 'Introduction to the method of Leonardo da Vinci', works of Paul Valéry, Vol.

8. Princeton, NJ: Princeton University Press. 
Le fou permet d'appréhender les possibilités-limites de la prise de conscience: il confronte la pensée discursive avec ce qui virtuellement se dérobe à l'articulation et à la réflexion.

Les Tabwa riverains du Lac au Shaba (Zaïre) appréhendent la folie sous un triple angle discursif. Wazimu, et kizenzezia qui en constitue la forme parvenue 'à maturitè' et incurable, est considérée d'emblée sous l'angle social, en tant qu'elle invertit les normes et les fonctions de la personnalité, défait celles de la mentalité et désarticule la réciprocité: cette forme de folie préfigure la 'Mort'. Deuxièment, c'est dans l'atteinte mubulibuli, et dans les états émotifs associés, que la folie apparait comme le produit du 'Désir' malicieux et intrusif de l'autre: le fou, dit-on, s'enferme dans son coeur pris de colère et se voit coupé de toute interaction et expérience en cours. Finalement, c'est dans le devin que 'l'altérité' du regard et du parler est transformée en une clairvoyance fondatrice de logique, d'histoire et de normes. L'inversion des attributs de la personne se mue ici en emblème de regard dévoileur et de 'Loi', tout en frôlant l'insanité. La rencontre ethnographique avec cette véritable altérité de la folie, ainsi qu'avec la pensée qu'une autre culture développe au sujet de l'impensé, s'avère être, dans un certain sens, épistémogénique. 